\title{
Photon-upconversion barcoding with multiple barcode channels: application for droplet microfluidics
}

Antonín Hlaváček, * Jana Křivánková, Jan Přikryl, František Foret

Institute of Analytical Chemistry of the Czech Academy of Sciences, 60200 Brno, Czech Republic

\section{Contents}

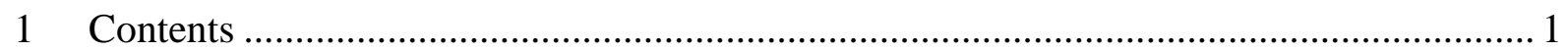

2 Synthesis of Photon-upconversion nanoparticles ........................................................ 2

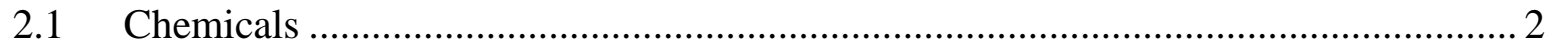

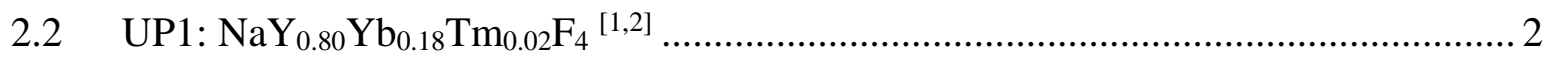

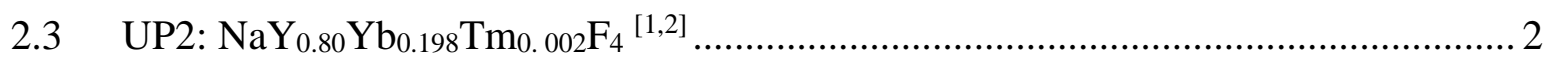

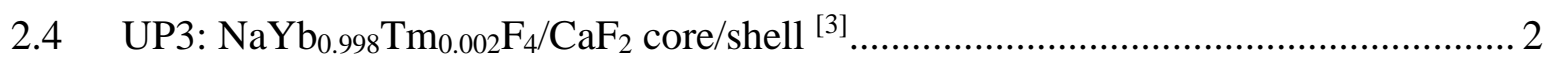

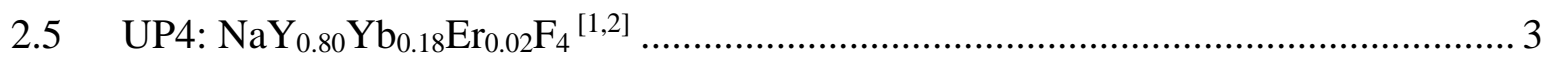

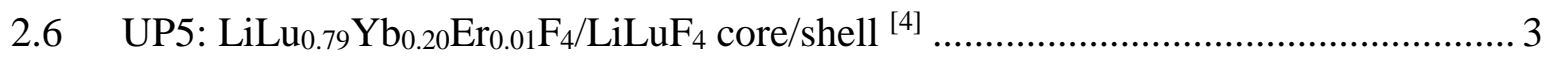

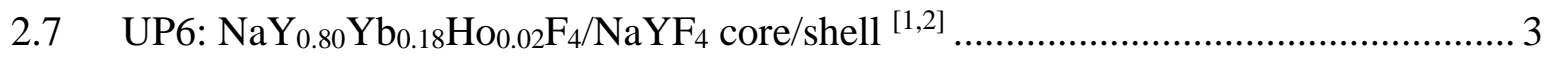

2.8 Nanoparticle coating with a carboxylated silica shell ......................................... 9

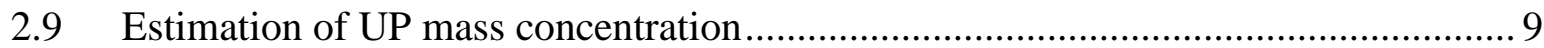

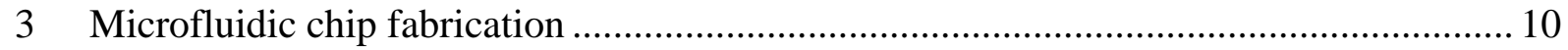

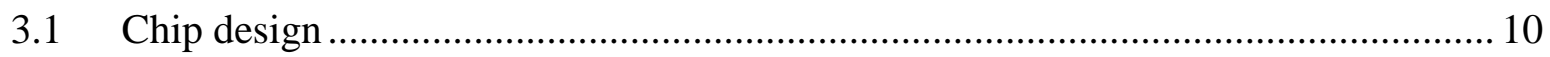

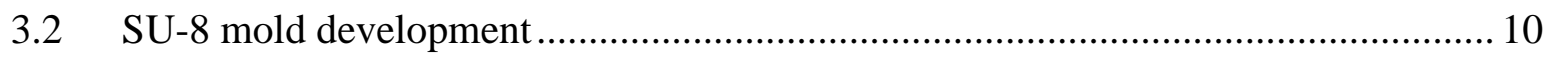

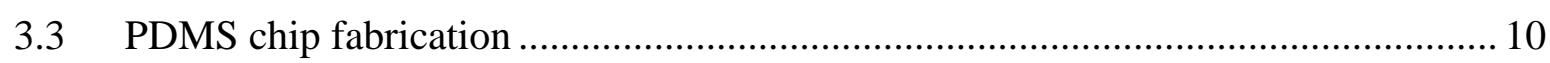

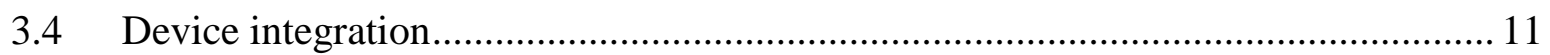

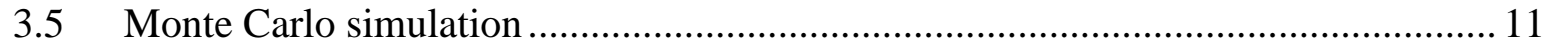

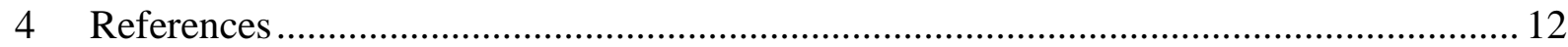




\section{Synthesis of Photon-upconversion nanoparticles}

\subsection{Chemicals}

$\mathrm{YCl}_{3} \times 6 \mathrm{H}_{2} \mathrm{O}(99.99 \%), \mathrm{YbCl}_{3} \times 6 \mathrm{H}_{2} \mathrm{O}(99.99 \%), \mathrm{TmCl}_{3} \times 6 \mathrm{H}_{2} \mathrm{O}(99.99 \%), \mathrm{ErCl}_{3} \times 6 \mathrm{H}_{2} \mathrm{O}(99.995 \%), \mathrm{Ho}_{2} \mathrm{O}_{3}$ (99.999\%), $\mathrm{Lu}_{2} \mathrm{O}_{3}(99.99 \%), \mathrm{Yb}_{2} \mathrm{O}_{3}(99.99 \%), \mathrm{Tm}_{2} \mathrm{O}_{3}(99.99 \%), \mathrm{Er}_{2} \mathrm{O}_{3}(99.99 \%), \mathrm{Li}_{2} \mathrm{CO}_{3}(\geq 99 \%)$, fluoroacetic acid $(99 \%), \mathrm{NH}_{4} \mathrm{~F}(>98 \%), 1$-octadecene $(90 \%)$, oleylamine $(70 \%)$, oleic acid $(90 \%)$, tetraethylorthosilicate (TEOS, $\geq 99 \%$ ) and Igepal CO-520 were purchased from Sigma-Aldrich (www.sigmaaldrich.com), and used as starting materials without further purification. $\mathrm{NaOH}$ (p.a.), cyclohexane (p.a.), $\mathrm{Ca}(\mathrm{OH})_{2}$ (p.a.), N,NDimethylformamide (p.a.) and $\mathrm{NH}_{4} \mathrm{OH} 25 \%$ (p.a.) was purchased from PENTA (Czech Republic) and carboxyethylsilanetriol, sodium salt; $25 \%$ (w/v) in water was obtained from ABCR GmbH (www.abcr.de). All other standard chemicals and diclofenac sodium salt were obtained from Sigma-Aldrich.

\section{$2.2 U P 1: \mathrm{NaY}_{0.80} \mathrm{Yb}_{0.18} \mathrm{Tm}_{0.02} \mathrm{~F}_{4}{ }^{[1,2]}$}

$\mathrm{YCl}_{3} \times 6 \mathrm{H}_{2} \mathrm{O}(971 \mathrm{mg}, 3.2 \mathrm{mmol}), \mathrm{YbCl}_{3} \times 6 \mathrm{H}_{2} \mathrm{O}(279 \mathrm{mg}, 0.72 \mathrm{mmol})$ and $\mathrm{TmCl}_{3} \times 6 \mathrm{H}_{2} \mathrm{O}(30.7 \mathrm{mg}, 0.08$ $\mathrm{mmol})$ were dissolved in methyl alcohol $(20 \mathrm{~mL})$ and added into a $100-\mathrm{mL}$ three-neck round-bottom flask containing oleic acid $(9 \mathrm{~g})$ and 1-octadecene $(19.7 \mathrm{~g})$. The solution was heated to $160{ }^{\circ} \mathrm{C}$ for 30 min under an $\mathrm{N}_{2}$ atmosphere and then cooled to $50{ }^{\circ} \mathrm{C}$. Then, the protective atmosphere was disconnected, and the solution of $\mathrm{NH}_{4} \mathrm{~F}$ $(593 \mathrm{mg}, 16.0 \mathrm{mmol})$ and $\mathrm{NaOH}(400 \mathrm{mg}, 10 \mathrm{mmol})$ in methyl alcohol $(20 \mathrm{~mL})$ was added to the intensively stirred solution. The $\mathrm{N}_{2}$ atmosphere was reconnected, and the solution was stirred for $30 \mathrm{~min}$. The temperature was carefully increased up to $150{ }^{\circ} \mathrm{C}$, avoiding extensive boiling to ensure the evaporation of methyl alcohol. After that, the solution was rapidly heated using the rate of $\sim 10{ }^{\circ} \mathrm{C}$ per minute. At $300{ }^{\circ} \mathrm{C}$, the heating was carefully regulated to $305{ }^{\circ} \mathrm{C}$ within two or three minutes. The flask was kept under $\mathrm{N}_{2}$ flow at $305{ }^{\circ} \mathrm{C}$ for 150 min. The fluctuation of temperature was $\pm 3{ }^{\circ} \mathrm{C}$ during this time. Finally, the flask was placed on another stirrer and rapidly cooled to room temperature under air flux. The resulting nanoparticles were precipitated by adding isopropyl alcohol $(30 \mathrm{~mL})$ and collected by centrifugation $(1,000 \times \mathrm{g}, 10 \mathrm{~min})$. The pellet was washed with methyl alcohol $(30 \mathrm{~mL})$, centrifuged $(1,000 \times \mathrm{g}, 10 \mathrm{~min})$ and dispersed in cyclohexane $(20 \mathrm{~mL})$. By adding methyl alcohol (100 $\mathrm{mL})$, the nanoparticles precipitated rapidly without the need for centrifugation. The precipitate was dispersed in cyclohexane $(30 \mathrm{~mL})$ and slowly centrifuged $(50 \times \mathrm{g}, 20 \mathrm{~min})$ to separate coarse particles from the final product.

\section{$2.3 U P 2: \mathrm{NaY}_{0.80} \mathrm{Yb}_{0.198} \mathrm{Tm}_{0.002} \mathrm{~F}_{4}{ }^{[1,2]}$}

$\mathrm{YCl}_{3} \times 6 \mathrm{H}_{2} \mathrm{O}(595 \mathrm{mg}, 1.96 \mathrm{mmol}), \mathrm{YbCl}_{3} \times 6 \mathrm{H}_{2} \mathrm{O}(167 \mathrm{mg}, 0.432 \mathrm{mmol})$ and $\mathrm{TmCl}_{3}(4.8 \mu \mathrm{mol}$, added as $96 \mu \mathrm{L}$ of $50 \mathrm{mM}$ water solution) were dissolved in methyl alcohol $(20 \mathrm{~mL})$ and added into a $100-\mathrm{mL}$ three-neck roundbottom flask containing oleic acid $(5.4 \mathrm{~g})$ and 1-octadecene $(11.8 \mathrm{~g})$. The solution was heated to $160{ }^{\circ} \mathrm{C}$ for $30 \mathrm{~min}$ under an $\mathrm{N}_{2}$ atmosphere and then cooled to $50{ }^{\circ} \mathrm{C}$. Then, the protective atmosphere was disconnected, and the solution of $\mathrm{NH}_{4} \mathrm{~F}$ (356 mg, $\left.9.6 \mathrm{mmol}\right)$ and $\mathrm{NaOH}(240 \mathrm{mg}, 6 \mathrm{mmol})$ in methyl alcohol $(20 \mathrm{~mL})$ was added to the intensively stirred solution. The $\mathrm{N}_{2}$ atmosphere was reconnected, and the solution was stirred for 30 min. The temperature was carefully increased up to $150^{\circ} \mathrm{C}$, avoiding extensive boiling to ensure the evaporation of methyl alcohol. After that, the solution was rapidly heated using the rate of $10{ }^{\circ} \mathrm{C}$ per minute. At $300{ }^{\circ} \mathrm{C}$, the heating was carefully regulated to $305{ }^{\circ} \mathrm{C}$ within two or three minutes. The flask was kept under $\mathrm{N}_{2}$ flow at $305^{\circ} \mathrm{C}$ for $150 \mathrm{~min}$. The fluctuation of temperature was $\pm 3{ }^{\circ} \mathrm{C}$ during this time. Finally, the flask was placed on another stirrer and rapidly cooled to room temperature under air flux. The resulting nanoparticles were precipitated by adding isopropyl alcohol $(20 \mathrm{~mL})$ and collected by centrifugation $(1,000 \times g, 10 \mathrm{~min})$. The pellet was washed with methyl alcohol $(20 \mathrm{~mL})$, centrifuged $(1,000 \times g, 10 \mathrm{~min})$ and dispersed in cyclohexane $(20 \mathrm{~mL})$. By adding methyl alcohol $(100 \mathrm{~mL})$, the nanoparticles precipitated rapidly without the need for centrifugation. The precipitate was dispersed in cyclohexane $(20 \mathrm{~mL})$ and slowly centrifuged $(50 \times g, 20 \mathrm{~min})$ to separate coarse particles from the final product.

\section{$2.4 U P 3: \mathrm{NaYb}_{0.998} \mathrm{Tm}_{0.002} \mathrm{~F}_{4} / \mathrm{CaF}_{2}$ core/shell ${ }^{[3]}$}

Step 1: core nanoparticles $\mathrm{NaY}_{0.998} \mathrm{Tm}_{0.002} \mathrm{~F}_{4}$. Under reflux, $\mathrm{NaHCO}_{3}(168 \mathrm{mg}, 2.00 \mathrm{mmol}), \mathrm{Tm}_{2} \mathrm{O}_{3}(0.4 \mathrm{mg}, 0.001$ $\mathrm{mmol}), \mathrm{Yb}_{2} \mathrm{O}_{3}(197 \mathrm{mg}, 0.499 \mathrm{mmol})$ were dissolved in trifluoroacetic acid $(2 \mathrm{~mL})$ and water $(2 \mathrm{~mL})$. Excessive trifluoroacetic acid and water were evaporated by heating at $100-120^{\circ} \mathrm{C}$ in a fume hood. The resulting white powder of trifluoroacetate was dissolved in oleic acid $(5.6 \mathrm{~g})$, oleylamine $(5.4 \mathrm{~g})$, and 1-octadecene $(10.0 \mathrm{~g})$. This solution was heated for $30 \mathrm{~min}$ at $120^{\circ} \mathrm{C}$ under the atmosphere of $\mathrm{N}_{2}$ and then rapidly heated to $300^{\circ} \mathrm{C}$ and kept at this temperature for $30 \mathrm{~min}$. Finally, the flask was cooled to room temperature. The resulting nanoparticles were precipitated by adding isopropyl alcohol $(20 \mathrm{~mL})$ and collected by centrifugation $(1,000 \times g, 10 \mathrm{~min})$. The pellet was washed with methyl alcohol $(20 \mathrm{~mL})$, centrifuged $(1,000 \times g, 10 \mathrm{~min})$ and dispersed in cyclohexane $(10 \mathrm{~mL})$. By adding methyl alcohol $(50 \mathrm{~mL})$, the nanoparticles precipitated rapidly without the need for centrifugation. The precipitate was dispersed in cyclohexane $(10 \mathrm{~mL})$ and slowly centrifuged $(50 \times \mathrm{g}, 20 \mathrm{~min})$ to separate coarse particles from the final product.

Step 2: core/shell nanoparticles $\mathrm{NaYb}_{0.998} \mathrm{Tm}_{0.002} \mathrm{~F}_{4} / \mathrm{CaF}_{2}$. Under reflux, $\mathrm{Ca}(\mathrm{OH})_{2}(148 \mathrm{mg}, 2.00 \mathrm{mmol})$ was dissolved in trifluoroacetic acid $(2 \mathrm{~mL})$ and water $(2 \mathrm{~mL})$. Excessive trifluoroacetic acid and water were evaporated by heating at $100-120^{\circ} \mathrm{C}$ in a fume hood. The resulting white powder of trifluoroacetate was dissolved in oleic acid $(11.4 \mathrm{~g})$ and 1-octadecene $(10.1 \mathrm{~g})$ with the addition of cyclohexane dispersion of core nanoparticles 
$\mathrm{NaYb}_{0.998} \mathrm{Tm}_{0.002} \mathrm{~F}_{4}$ prepared in step 1. This solution was heated for $30 \mathrm{~min}$ at $120^{\circ} \mathrm{C}$ under the atmosphere of $\mathrm{N}_{2}$ and then rapidly heated to $300^{\circ} \mathrm{C}$ and kept at this temperature for $30 \mathrm{~min}$. Finally, the flask was cooled to room temperature. The resulting nanoparticles were precipitated by adding isopropyl alcohol $(20 \mathrm{~mL})$ and collected by centrifugation $(1,000 \times g, 10 \mathrm{~min})$. The pellet was washed with methyl alcohol $(20 \mathrm{~mL})$, centrifuged $(1,000 \times g$, $10 \mathrm{~min})$ and dispersed in cyclohexane $(10 \mathrm{~mL})$. By adding methyl alcohol $(50 \mathrm{~mL})$, the nanoparticles precipitated rapidly without the need for centrifugation. The precipitate was dispersed in cyclohexane (10 $\mathrm{mL})$ and slowly centrifuged $(50 \times g, 20 \mathrm{~min})$ to separate coarse particles from the final product.

\section{$2.5 U P 4: \mathrm{NaY}_{0.80} \mathrm{Yb}_{0.18} \mathrm{Er}_{0.02} \mathrm{~F}_{4}^{[1,2]}$}

$\mathrm{YCl}_{3} \times 6 \mathrm{H}_{2} \mathrm{O}(1165 \mathrm{mg}, 3.84 \mathrm{mmol}), \mathrm{YbCl}_{3} \times 6 \mathrm{H}_{2} \mathrm{O}(335 \mathrm{mg}, 0.864 \mathrm{mmol})$ and $\mathrm{ErCl}_{3} \times 6 \mathrm{H}_{2} \mathrm{O}(36.6 \mathrm{mg}, 0.096$ $\mathrm{mmol})$ were dissolved in methyl alcohol $(20 \mathrm{~mL})$ and added into a $100-\mathrm{mL}$ three-neck round-bottom flask containing oleic acid $(10.8 \mathrm{~g})$ and 1-octadecene $(23.6 \mathrm{~g})$. The solution was heated to $160{ }^{\circ} \mathrm{C}$ for 30 min under an $\mathrm{N}_{2}$ atmosphere and then cooled to $50{ }^{\circ} \mathrm{C}$. Then, the protective atmosphere was disconnected, and the solution of $\mathrm{NH}_{4} \mathrm{~F}(711 \mathrm{mg}, 19.2 \mathrm{mmol})$ and $\mathrm{NaOH}(480 \mathrm{mg}, 12 \mathrm{mmol})$ in methyl alcohol $(20 \mathrm{~mL})$ was added to the intensively stirred solution. The $\mathrm{N}_{2}$ atmosphere was reconnected, and the solution was stirred for $30 \mathrm{~min}$. The temperature was carefully increased up to $150^{\circ} \mathrm{C}$, avoiding extensive boiling to ensure the evaporation of methyl alcohol. After that, the solution was rapidly heated using the rate of $10{ }^{\circ} \mathrm{C}$ per minute. At $300{ }^{\circ} \mathrm{C}$, the heating was carefully regulated to $305{ }^{\circ} \mathrm{C}$ within two or three minutes. The flask was kept under $\mathrm{N}_{2}$ flow at $305{ }^{\circ} \mathrm{C}$ for 150 min. The fluctuation of temperature was $\pm 3^{\circ} \mathrm{C}$ during this time. Finally, the flask was placed on another stirrer and rapidly cooled to room temperature under air flux. The resulting nanoparticles were precipitated by adding isopropyl alcohol $(40 \mathrm{~mL})$ and collected by centrifugation $(1,000 \times \mathrm{g}, 10 \mathrm{~min})$. The pellet was washed with methyl alcohol $(40 \mathrm{~mL})$, centrifuged $(1,000 \times \mathrm{g}, 10 \mathrm{~min})$ and dispersed in cyclohexane $(20 \mathrm{~mL})$. By adding methyl alcohol (100 $\mathrm{mL})$, the nanoparticles precipitated rapidly without the need for centrifugation. The precipitate was dispersed in cyclohexane $(30 \mathrm{~mL})$ and slowly centrifuged $(50 \times \mathrm{g}, 20 \mathrm{~min})$ to separate coarse particles from the final product.

\subsection{UP5: LiLu ${ }_{0.79} \mathrm{Yb}_{0.20} \mathrm{Er}_{0.01} \mathrm{~F}_{4} / \mathrm{LiLuF}_{4}$ core/shell ${ }^{[4]}$}

Precursor solution A: Under reflux, $\mathrm{Li}_{2} \mathrm{CO}_{3}(36.9 \mathrm{mg}, 0.500 \mathrm{mmol}), \mathrm{Lu}_{2} \mathrm{O}_{3}(157 \mathrm{mg}, 0.395 \mathrm{mmol}), \mathrm{Yb}_{2} \mathrm{O}_{3}(39.4$ $\mathrm{mg}, 0.100 \mathrm{mmol})$ and $\mathrm{Er}_{2} \mathrm{O}_{3}(1.9 \mathrm{mg}, 0.005 \mathrm{mmol})$ were dissolved in trifluoroacetic acid $(2 \mathrm{~mL})$ and water $(2 \mathrm{~mL})$. Excessive trifluoroacetic acid and water were evaporated by heating at $100-120^{\circ} \mathrm{C}$ in a fume hood. The resulting white powder of trifluoroacetate was dissolved in oleic acid $(5.4 \mathrm{~g})$, oleylamine $(1.6 \mathrm{~g})$ and 1-octadecene $(1.6 \mathrm{~g})$ forming the "precursor solution A".

Precursor solution $B$ : Under reflux, $\mathrm{Li}_{2} \mathrm{CO}_{3}(73.9 \mathrm{mg}, 1.00 \mathrm{mmol})$ and $\mathrm{Lu}_{2} \mathrm{O}_{3}(388 \mathrm{mg}, 1.00 \mathrm{mmol})$ were dissolved in trifluoroacetic acid $(4 \mathrm{~mL})$ and water $(4 \mathrm{~mL})$. Excessive trifluoroacetic acid and water were evaporated by heating at $100-120^{\circ} \mathrm{C}$ in a fume hood. The resulting white powder of trifluoroacetate was dissolved in oleic acid $(16.0 \mathrm{~g})$, oleylamine $(18.0 \mathrm{~g})$ and 1-octadecene $(4.0 \mathrm{~g})$ forming the "precursor solution B."

Nanoparticle synthesis: Before synthesis, solution A and B were heated at $120^{\circ} \mathrm{C}$ for 30 min under $\mathrm{N}_{2}$ atmosphere. The temperature of solution A was rapidly increased to $320^{\circ} \mathrm{C}$ and hold at this temperature for 40 min, which resulted in the formation of core nanoparticles $\left(\mathrm{LiLu}_{0.79} \mathrm{Yb}_{0.20} \mathrm{Er}_{0.01} \mathrm{~F}_{4}\right)$. Without decreasing the temperature, solution $\mathrm{B}(2 \mathrm{~mL})$ was sixteen times injected into hot solution A (containing freshly formed core nanoparticles) with 10 min delay between injections. The resulting $\mathrm{LiLu}_{0.79} \mathrm{Yb}_{0.20} \mathrm{Er}_{0.01} \mathrm{~F}_{4} / \mathrm{LiLuF}_{4}$ core/shell nanoparticles were precipitated by adding isopropyl alcohol $(50 \mathrm{~mL})$ and collected by centrifugation $(1,000 \times g, 10 \mathrm{~min})$. The pellet was washed with methyl alcohol $(50 \mathrm{~mL})$, centrifuged $(1,000 \times g, 10 \mathrm{~min})$ and dispersed in cyclohexane $(20 \mathrm{~mL})$. By adding methyl alcohol $(100 \mathrm{~mL})$, the nanoparticles precipitated rapidly without the need for centrifugation. The precipitate was dispersed in cyclohexane $(20 \mathrm{~mL})$ and slowly centrifuged $(50 \times g, 20 \mathrm{~min})$ to separate coarse particles from the final product.

\subsection{UP6: $\mathrm{NaY}_{0.80} \mathrm{Yb}_{0.18} \mathrm{Ho}_{0.02} \mathrm{~F}_{4} / \mathrm{NaYF}_{4}$ core/shell ${ }^{[1,2]}$}

Step 1: core nanoparticles $\mathrm{NaY}_{0.80} \mathrm{Yb}_{0.18} \mathrm{Ho}_{0.02} \mathrm{~F}_{4} . \mathrm{YCl}_{3} \times 6 \mathrm{H}_{2} \mathrm{O}(971 \mathrm{mg}, 3.2 \mathrm{mmol}), \mathrm{YbCl}_{3} \times 6 \mathrm{H}_{2} \mathrm{O}(279 \mathrm{mg}, 0.72$ $\mathrm{mmol})$ and $\mathrm{HoCl}_{3}\left(0.08 \mathrm{mmol}\right.$, prepared by dissolving $\mathrm{Ho}_{2} \mathrm{O}_{3}-0.04 \mathrm{mmol}, 15.1 \mathrm{mg}-$ in $\left.15 \% \mathrm{HCl}\right)$ were dissolved in methyl alcohol $(20 \mathrm{~mL})$ and added into a $100-\mathrm{mL}$ three-neck round-bottom flask containing oleic acid $(9 \mathrm{~g})$ and 1-octadecene $(19.7 \mathrm{~g})$. The solution was heated to $160{ }^{\circ} \mathrm{C}$ for $30 \mathrm{~min}$ under an $\mathrm{N}_{2}$ atmosphere and then cooled to $50{ }^{\circ} \mathrm{C}$. Then, the protective atmosphere was disconnected, and the solution of $\mathrm{NH}_{4} \mathrm{~F}(593 \mathrm{mg}, 16 \mathrm{mmol})$ and $\mathrm{NaOH}$ (400 mg, $10 \mathrm{mmol})$ in methyl alcohol $(20 \mathrm{~mL})$ was added to the intensively stirred solution. The $\mathrm{N}_{2}$ atmosphere was reconnected, and the solution was stirred for $30 \mathrm{~min}$. The temperature was carefully increased up to $150{ }^{\circ} \mathrm{C}$, avoiding extensive boiling to ensure the evaporation of methyl alcohol. After that, the solution was rapidly heated using the rate of $10{ }^{\circ} \mathrm{C}$ per minute. At $300{ }^{\circ} \mathrm{C}$, the heating was carefully regulated to $305^{\circ} \mathrm{C}$ within two or three minutes. The flask was kept under $\mathrm{N}_{2}$ flow at $305{ }^{\circ} \mathrm{C}$ for $150 \mathrm{~min}$. The fluctuation of temperature was $\pm 3{ }^{\circ} \mathrm{C}$ during this time. Finally, the flask was placed on another stirrer and rapidly cooled to room temperature under air flux. The resulting nanoparticles were precipitated by adding isopropyl alcohol $(40 \mathrm{~mL})$ and collected by centrifugation $(1,000 \times g, 10 \mathrm{~min})$. The pellet was washed with methyl alcohol $(40 \mathrm{~mL})$, centrifuged $(1,000 \times g$, $10 \mathrm{~min})$ and dispersed in cyclohexane $(20 \mathrm{~mL})$. By adding methyl alcohol $(100 \mathrm{~mL})$, the nanoparticles precipitated rapidly without the need for centrifugation. The precipitate was dispersed in cyclohexane (30 $\mathrm{mL})$ and slowly centrifuged $(50 \times g, 20 \mathrm{~min})$ to separate coarse particles from the final product. 
Step 2: core/shell $\mathrm{NaY}_{0.80} \mathrm{Yb}_{0.18} \mathrm{Ho}_{0.02} \mathrm{~F}_{4} / \mathrm{NaYF}_{4} . \mathrm{YCl}_{3} \times 6 \mathrm{H}_{2} \mathrm{O}(607 \mathrm{mg}, 2.0 \mathrm{mmol})$ was dissolved in methyl alcohol $(10 \mathrm{~mL})$ and added into a $100-\mathrm{mL}$ three-neck round-bottom flask containing oleic acid $(9 \mathrm{~g})$ and 1-octadecene $(19.7 \mathrm{~g})$. The solution was heated to $160{ }^{\circ} \mathrm{C}$ for $30 \mathrm{~min}$ under an $\mathrm{N}_{2}$ atmosphere and then cooled to $50{ }^{\circ} \mathrm{C}$. Then, the protective atmosphere was disconnected, and the solutions of (A) $\mathrm{NH}_{4} \mathrm{~F}$ (296 mg, $\left.8 \mathrm{mmol}\right), \mathrm{NaOH}(200 \mathrm{mg}, 5$ $\mathrm{mmol}$ ) in methyl alcohol $(20 \mathrm{~mL})$ and (B) $310 \mathrm{mg}$ of core nanoparticles $\mathrm{NaY}_{0.80} \mathrm{Yb}_{0.18} \mathrm{Ho}_{0.02} \mathrm{~F}_{4}$ in cyclohexane (10 $\mathrm{mL}$ ) were added to the intensively stirred solution. The $\mathrm{N}_{2}$ atmosphere was reconnected, and the solution was stirred for $30 \mathrm{~min}$. The temperature was carefully increased up to $150{ }^{\circ} \mathrm{C}$, avoiding extensive boiling to ensure the evaporation of methyl alcohol. After that, the solution was rapidly heated using the rate of $10^{\circ} \mathrm{C}$ per minute. At $300{ }^{\circ} \mathrm{C}$, the heating was carefully regulated to $305^{\circ} \mathrm{C}$ within two or three minutes. The flask was kept under $\mathrm{N}_{2}$ flow at $305^{\circ} \mathrm{C}$ for $90 \mathrm{~min}$. The fluctuation of temperature was $\pm 3{ }^{\circ} \mathrm{C}$ during this time. Finally, the flask was placed on another stirrer and rapidly cooled to room temperature under air flux. The resulting nanoparticles were precipitated by adding isopropyl alcohol $(40 \mathrm{~mL})$ and collected by centrifugation $(1,000 \times g, 10 \mathrm{~min})$. The pellet was washed with methyl alcohol $(40 \mathrm{~mL})$, centrifuged $(1,000 \times g, 10 \mathrm{~min})$ and dispersed in cyclohexane $(20 \mathrm{~mL})$. By adding methyl alcohol $(100 \mathrm{~mL})$, the nanoparticles precipitated rapidly without the need for centrifugation. The precipitate was dispersed in cyclohexane $(20 \mathrm{~mL})$ and slowly centrifuged $(50 \times g, 20 \mathrm{~min})$ to separate coarse particles from the final product. 
Table S1. Quantum yields of photon-upconversion materials

\begin{tabular}{|c|c|c|c|c|c|c|c|}
\hline \multirow{2}{*}{$\begin{array}{l}\text { Nanoparticles used in this work } \\
\text { Type }\end{array}$} & \multicolumn{7}{|c|}{ Similar nanoparticles with a known quantum yield } \\
\hline & Type & Size & $\begin{array}{l}\text { Excitation } \\
\text { wavelength }\end{array}$ & $\begin{array}{l}\text { Power } \\
\text { denisty }\end{array}$ & $\begin{array}{l}\text { Quantum } \\
\text { yield }\end{array}$ & $\begin{array}{l}\text { Dispersion } \\
\text { medium }\end{array}$ & Ref. \\
\hline \multirow{8}{*}{$\begin{array}{l}\text { UP1: } \mathrm{NaY}_{0.80} \mathrm{Yb}_{0.18} \mathrm{Tm}_{0.02} \mathrm{~F}_{4} \\
\text { and UP2: } \mathrm{NaY}_{0.80} \mathrm{Yb}_{0.198} \mathrm{Tm}_{0.002} \mathrm{~F}_{4}\end{array}$} & $\mathrm{NaY}_{0.747} \mathrm{Yb}_{0.25} \mathrm{Tm}_{0.003} \mathrm{~F}_{4} @ \mathrm{NaYF}_{4}$ & $42 \mathrm{~nm}$ & $975 \mathrm{~nm}$ & $78 \mathrm{~W} \mathrm{~cm}^{-2}$ & $3.5 \%$ & Hexane & 5 \\
\hline & $\mathrm{NaY}_{0.747} \mathrm{Yb}_{0.25} \mathrm{Tm}_{0.003} \mathrm{~F}_{4}$ & $33 \mathrm{~nm}$ & $975 \mathrm{~nm}$ & $3.8 \mathrm{~W} \mathrm{~cm}^{-2}$ & $0.45 \%$ & Hexane & 6 \\
\hline & $\mathrm{NaY}_{0.747} \mathrm{Yb}_{0.25} \mathrm{Tm}_{0.003} \mathrm{~F}_{4} @ \mathrm{NaYF}_{4}$ & $43 \mathrm{~nm}$ & & $1.3 \mathrm{~W} \mathrm{~cm}^{-2}$ & $1.2 \%$ & & \\
\hline & $\mathrm{NaY}_{0.745} \mathrm{Yb}_{0.25} \mathrm{Tm}_{0.005} \mathrm{~F}_{4}$ & $32 \mathrm{~nm}$ & $975 \mathrm{~nm}$ & $14 \mathrm{~W} \mathrm{~cm}^{-2}$ & $0.39 \%$ & Cyclohexane & 7 \\
\hline & $\mathrm{LiY}_{0.745} \mathrm{Yb}_{0.25} \mathrm{Tm}_{0.005} \mathrm{~F}_{4}$ & $\begin{array}{l}87 \times 50 \\
\mathrm{~nm}\end{array}$ & $976 \mathrm{~nm}$ & $5.5 \mathrm{~W} \mathrm{~cm}^{-2}$ & $1.9 \%$ & Toluen & 8 \\
\hline & & & & $48 \mathrm{~W} \mathrm{~cm}^{-2}$ & $2.6 \%$ & & \\
\hline & & & & $212 \mathrm{~W} \mathrm{~cm}^{-2}$ & $3.5 \%$ & & \\
\hline & & & & $395 \mathrm{~W} \mathrm{~cm}^{-2}$ & $3.7 \%$ & & \\
\hline $\begin{array}{l}\text { UP3: } \mathrm{NaYb}_{0.998} \mathrm{Tm}_{0.002} \mathrm{~F}_{4} \\
@ \mathrm{CaF}_{2}\end{array}$ & $\begin{array}{l}\mathrm{NaYb}_{0.995} \mathrm{Tm}_{0.005} \mathrm{~F}_{4} \\
\text { @ } \mathrm{CaF}_{2}\end{array}$ & $20 \mathrm{~nm}$ & $975 \mathrm{~nm}$ & $0.3 \mathrm{~W} \mathrm{~cm}^{-2}$ & $\begin{array}{l}0.6 \pm \\
0.1 \%\end{array}$ & Hexane & 3 \\
\hline \multirow[t]{20}{*}{ UP4: $\mathrm{NaY}_{0.80} \mathrm{Yb}_{0.18} \mathrm{Er}_{0.02} \mathrm{~F}_{4}$} & $\mathrm{NaY}_{0.80} \mathrm{Yb}_{0.17} \mathrm{Er}_{0.03} \mathrm{~F}_{4}$ & $\begin{array}{l}23 \times \\
26-30 \\
\mathrm{~nm}\end{array}$ & $976 \mathrm{~nm}$ & $\begin{array}{l}20 \mathrm{~W} \mathrm{~cm}^{-2} \\
410 \mathrm{~W} \mathrm{~cm}^{-2}\end{array}$ & $\begin{array}{l}0.098 \% \\
1.44 \%\end{array}$ & Toluen & 9 \\
\hline & $\mathrm{NaY}_{0.764} \mathrm{Yb}_{0.214} \mathrm{Er}_{0.022} \mathrm{~F}_{4}$ & $3 \mu \mathrm{m}$ & & $20 \mathrm{~W} \mathrm{~cm}^{-2}$ & $10.3 \%$ & No dispersion & \\
\hline & & & & $130 \mathrm{~W} \mathrm{~cm}^{-2}$ & $8.3 \%$ & & \\
\hline & $\mathrm{NaY}_{0.78} \mathrm{Yb}_{0.20} \mathrm{Er}_{0.02} \mathrm{~F}_{4}$ & $\begin{array}{l}>>100 \\
\mathrm{~nm}\end{array}$ & $980 \mathrm{~nm}$ & $20 \mathrm{~W} \mathrm{~cm}^{-2}$ & $\begin{array}{l}3.0 \pm \\
0.3 \%\end{array}$ & $\begin{array}{l}\text { No dispersion } \\
\text { medium }\end{array}$ & 10 \\
\hline & $\mathrm{NaY}_{0.78} \mathrm{Yb}_{0.20} \mathrm{Er}_{0.02} \mathrm{~F}_{4}$ & $100 \mathrm{~nm}$ & & $150 \mathrm{~W} \mathrm{~cm}^{-2}$ & $\begin{array}{l}0.30 \pm \\
0.10 \%\end{array}$ & Hexane & \\
\hline & $\mathrm{NaY}_{0.78} \mathrm{Yb}_{0.20} \mathrm{Er}_{0.02} \mathrm{~F}_{4}$ & $30 \mathrm{~nm}$ & & & $\begin{array}{l}0.10 \pm \\
0.05 \%\end{array}$ & & \\
\hline & $\mathrm{NaY}_{0.78} \mathrm{Yb}_{0.20} \mathrm{Er}_{0.02} \mathrm{~F}_{4}$ & $\begin{array}{l}8-10 \\
\mathrm{~nm}\end{array}$ & & & $\begin{array}{l}0.005 \pm \\
0.005 \%\end{array}$ & & \\
\hline & $\mathrm{NaY}_{0.78} \mathrm{Yb}_{0.20} \mathrm{Er}_{0.02} \mathrm{~F}_{4}$ & $30 \mathrm{~nm}$ & & & $\begin{array}{l}0.30 \pm \\
0.10 \%\end{array}$ & & \\
\hline & $\mathrm{NaY}_{0.78} \mathrm{Yb}_{0.20} \mathrm{Er}_{0.02} \mathrm{~F}_{4}$ & $23 \mathrm{~nm}$ & $976 \mathrm{~nm}$ & $\begin{array}{l}\sim 950 \mathrm{~W} \\
\mathrm{~cm}^{-2}\end{array}$ & $\sim 1 \%$ & Cyclohexane & 11 \\
\hline & & & & $\begin{array}{l}\sim 950 \mathrm{~W} \\
\mathrm{~cm}^{-2}\end{array}$ & $\sim 1 \%$ & $\begin{array}{l}\mathrm{N}, \mathrm{N}- \\
\text { Dimethylform } \\
\text { amide }\end{array}$ & \\
\hline & & & & $\begin{array}{l}\sim 800 \mathrm{~W} \\
\mathrm{~cm}^{-2}\end{array}$ & $\sim 0.5 \%$ & $\mathrm{H}_{2} \mathrm{O}$ & \\
\hline & & & & $\begin{array}{l}\sim 850 \mathrm{~W} \\
\mathrm{~cm}^{-2}\end{array}$ & $\sim 1 \%$ & $\mathrm{D}_{2} \mathrm{O}$ & \\
\hline & $\mathrm{NaY}_{0.86} \mathrm{Yb}_{0.11} \mathrm{Er}_{0.03} \mathrm{~F}_{4}$ & $\begin{array}{l}33.4 \\
\mathrm{~nm}\end{array}$ & $976 \mathrm{~nm}$ & $20 \mathrm{~W} \mathrm{~cm}^{-2}$ & $0.34 \%$ & Toluen & 12 \\
\hline & & & & $380 \mathrm{~W} \mathrm{~cm}^{-2}$ & $2.50 \%$ & & \\
\hline & $\mathrm{NaY}_{0.83} \mathrm{Yb}_{0.14} \mathrm{Er}_{0.03} \mathrm{~F}_{4}$ & $\begin{array}{l}34.0 \\
\mathrm{~nm}\end{array}$ & & $20 \mathrm{~W} \mathrm{~cm}^{-2}$ & $0.30 \%$ & & \\
\hline & & & & $380 \mathrm{~W} \mathrm{~cm}^{-2}$ & $2.30 \%$ & & \\
\hline & $\mathrm{NaY}_{0.80} \mathrm{Yb}_{0.17} \mathrm{Er}_{0.03} \mathrm{~F}_{4}$ & $\begin{array}{l}33.8 \\
\mathrm{~nm}\end{array}$ & & $20 \mathrm{~W} \mathrm{~cm}^{-2}$ & $0.22 \%$ & & \\
\hline & & & & $380 \mathrm{~W} \mathrm{~cm}^{-2}$ & $1.96 \%$ & & \\
\hline & $\mathrm{NaY}_{0.76} \mathrm{Yb}_{0.21} \mathrm{Er}_{0.03} \mathrm{~F}_{4}$ & $\begin{array}{l}34.2 \\
\mathrm{~nm}\end{array}$ & & $20 \mathrm{~W} \mathrm{~cm}^{-2}$ & $0.16 \%$ & & \\
\hline & & & & $380 \mathrm{~W} \mathrm{~cm}^{-2}$ & $1.73 \%$ & & \\
\hline
\end{tabular}




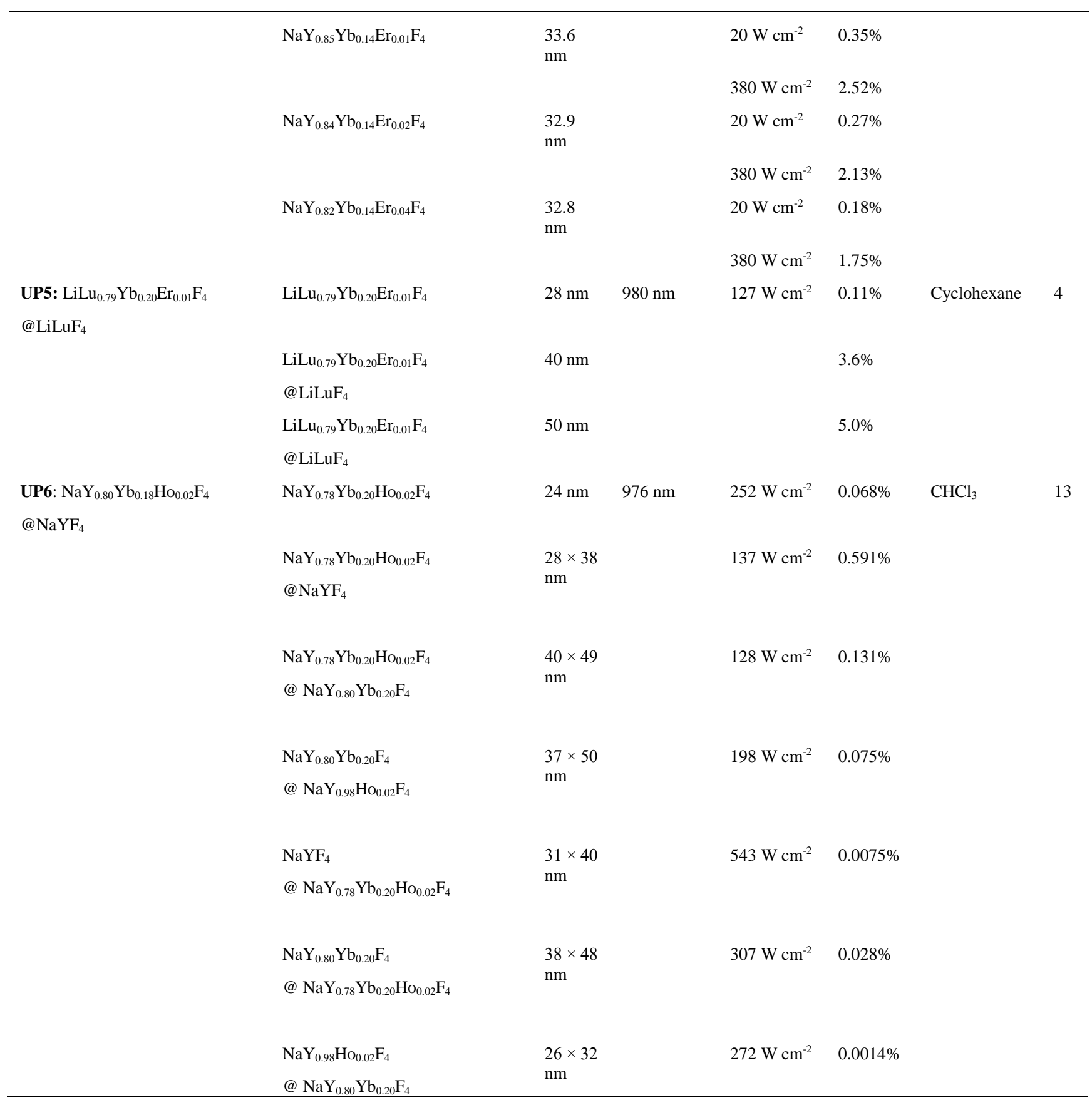


Table S2. Previously published photon-upconversion lifetimes of photon-upconversion materials

\begin{tabular}{|c|c|c|c|c|c|c|}
\hline \multirow{2}{*}{$\begin{array}{l}\text { Nanoparticles used in this } \\
\text { work }\end{array}$} & \multicolumn{6}{|c|}{ Similar nanoparticles with a known luminescence lifetime } \\
\hline & Type & Size & $\begin{array}{l}\text { Excitation } \\
\text { wavelength }\end{array}$ & $\begin{array}{l}\text { Photon-upconversion } \\
\text { luminescence lifetimes }\end{array}$ & $\begin{array}{l}\text { Dispersion } \\
\text { medium }\end{array}$ & Ref. \\
\hline \multirow{10}{*}{$\begin{array}{l}\text { UP1 and UP2 } \\
\left(\mathrm{NaY}_{0.80} \mathrm{Yb}_{0.18} \mathrm{Tm}_{0.02} \mathrm{~F}_{4} \text { and }\right. \\
\left.\mathrm{NaY}_{0.80} \mathrm{Yb}_{0.198} \mathrm{Tm}_{0.002} \mathrm{~F}_{4}\right)\end{array}$} & $\mathrm{NaY}_{0.795} \mathrm{Yb}_{0.20} \mathrm{Tm}_{0.005} \mathrm{~F}_{4}$ & $29-32 \mathrm{~nm}$ & $976 \mathrm{~nm}$ & $666 \pm 2.5 \mu \mathrm{s}\left(\lambda_{\mathrm{em}} 798 \mathrm{~nm}\right)$ & $\mathrm{H}_{2} \mathrm{O}$ & 14 \\
\hline & & & & $708 \pm 79.4 \mu \mathrm{s}\left(\lambda_{\mathrm{em}} 650 \mathrm{~nm}\right)$ & & \\
\hline & & & & $593 \pm 10.9 \mu \mathrm{s}\left(\lambda_{\mathrm{em}} 474 \mathrm{~nm}\right)$ & & \\
\hline & $\mathrm{NaY}_{0.72} \mathrm{Yb}_{0.20} \mathrm{Tm}_{0.08} \mathrm{~F}_{4}$ & $\sim 40 \mathrm{~nm}$ & $980 \mathrm{~nm}$ & $26 \mu \mathrm{s}\left(\lambda_{\mathrm{em}} 475 \mathrm{~nm}\right)$ & Water buffer & 15 \\
\hline & $\mathrm{NaY}_{0.76} \mathrm{Yb}_{0.20} \mathrm{Tm}_{0.04} \mathrm{~F}_{4}$ & & & $58 \mu \mathrm{s}$ & & \\
\hline & $\mathrm{NaY}_{0.69} \mathrm{Yb}_{0.30} \mathrm{Tm}_{0.01} \mathrm{~F}_{4}$ & & & $120 \mu \mathrm{s}$ & & \\
\hline & $\mathrm{NaY}_{0.79} \mathrm{Yb}_{0.20} \mathrm{Tm}_{0.01} \mathrm{~F}_{4}$ & & & $155 \mu \mathrm{s}$ & & \\
\hline & $\mathrm{NaY}_{0.89} \mathrm{Yb}_{0.10} \mathrm{Tm}_{0.01} \mathrm{~F}_{4}$ & & & $207 \mu \mathrm{s}$ & & \\
\hline & $\mathrm{NaY}_{0.795} \mathrm{Yb}_{0.20} \mathrm{Tm}_{0.005} \mathrm{~F}_{4}$ & & & $370 \mu \mathrm{s}$ & & \\
\hline & $\mathrm{NaY}_{0.798} \mathrm{Yb}_{0.20} \mathrm{Tm}_{0.002} \mathrm{~F}_{4}$ & & & $662 \mu \mathrm{s}$ & & \\
\hline \multirow{2}{*}{$\begin{array}{l}\text { UP3: } \mathrm{NaYb}_{0.998} \mathrm{Tm}_{0.002} \mathrm{~F}_{4} \\
\text { @ } \mathrm{CaF}_{2}\end{array}$} & $\mathrm{NaYb}_{0.995} \mathrm{Tm}_{0.005} \mathrm{~F}_{4}$ & $20 \mathrm{~nm}$ & $975 \mathrm{~nm}$ & $90 \mu \mathrm{s}\left(\lambda_{\mathrm{em}} 802 \mathrm{~nm}\right)$ & Hexane & 3 \\
\hline & $\mathrm{NaYb}_{0.995} \mathrm{Tm}_{0.005} \mathrm{~F}_{4} @ \mathrm{CaF}_{2}$ & $27 \mathrm{~nm}$ & $975 \mathrm{~nm}$ & $300 \mu \mathrm{s}\left(\lambda_{\mathrm{em}} 802 \mathrm{~nm}\right)$ & Hexane & \\
\hline \multirow[t]{18}{*}{ UP4: $\mathrm{NaY}_{0.80} \mathrm{Yb}_{0.18} \mathrm{Er}_{0.02} \mathrm{~F}_{4}$} & $\mathrm{NaY}_{0.80} \mathrm{Yb}_{0.17} \mathrm{Er}_{0.03} \mathrm{~F}_{4}$ & $31-38 \mathrm{~nm}$ & $976 \mathrm{~nm}$ & $81 \pm 1.5 \mu \mathrm{s}\left(\lambda_{\mathrm{em}} 524 \mathrm{~nm}\right)$ & $\mathrm{H}_{2} \mathrm{O}$ & 14 \\
\hline & & & & $296 \pm 10.8 \mu \mathrm{s}\left(\lambda_{\mathrm{em}} 658 \mathrm{~nm}\right)$ & & \\
\hline & $\mathrm{NaY}_{0.78} \mathrm{Yb}_{0.20} \mathrm{Er}_{0.02} \mathrm{~F}_{4}$ & $23 \mathrm{~nm}$ & $980 \mathrm{~nm}$ & $69 \mu \mathrm{s}\left(\lambda_{\mathrm{em}} 545 \mathrm{~nm}\right)$ & $\mathrm{H}_{2} \mathrm{O}$ & 11 \\
\hline & & & & $185 \mu \mathrm{s}\left(\lambda_{\mathrm{em}} 655 \mathrm{~nm}\right)$ & & \\
\hline & $\mathrm{NaY}_{0.78} \mathrm{Yb}_{0.20} \mathrm{Er}_{0.02} \mathrm{~F}_{4}$ & $8 \mathrm{~nm}$ & $980 \mathrm{~nm}$ & $36 \mu \mathrm{s}\left(\lambda_{\mathrm{em}} 532-700 \mathrm{~nm}\right)$ & Measured on & 16 \\
\hline & & $30 \mathrm{~nm}$ & & $93 \mu \mathrm{s}$ & nanoparticles & \\
\hline & & $50 \mathrm{~nm}$ & & $123 \mu \mathrm{s}$ & & \\
\hline & & $150 \mathrm{~nm}$ & & $153 \mu \mathrm{s}$ & & \\
\hline & $\mathrm{NaY}_{0.78} \mathrm{Yb}_{0.20} \mathrm{Er}_{0.02} \mathrm{~F}_{4}$ & $12 \mathrm{~nm}$ & $980 \mathrm{~nm}$ & $78 \mu \mathrm{s}\left(\lambda_{\mathrm{em}} 540 \mathrm{~nm}\right)$ & Cyclohexane & 17 \\
\hline & & & & $85 \mu \mathrm{s}\left(\lambda_{\mathrm{em}} 655 \mathrm{~nm}\right)$ & & \\
\hline & & $21 \mathrm{~nm}$ & & $92 \mu \mathrm{s}\left(\lambda_{\mathrm{em}} 540 \mathrm{~nm}\right)$ & & \\
\hline & & & & $194 \mu \mathrm{s}\left(\lambda_{\mathrm{em}} 655 \mathrm{~nm}\right)$ & & \\
\hline & & $26 \mathrm{~nm}$ & & $116 \mu \mathrm{s}\left(\lambda_{\mathrm{em}} 540 \mathrm{~nm}\right)$ & & \\
\hline & & & & $211 \mu \mathrm{s}\left(\lambda_{\mathrm{em}} 655 \mathrm{~nm}\right)$ & & \\
\hline & & $31 \mathrm{~nm}$ & & $136 \mu \mathrm{s}\left(\lambda_{\mathrm{em}} 540 \mathrm{~nm}\right)$ & & \\
\hline & & & & $249 \mu \mathrm{s}\left(\lambda_{\mathrm{em}} 655 \mathrm{~nm}\right)$ & & \\
\hline & & $43 \mathrm{~nm}$ & & $213 \mu \mathrm{s}\left(\lambda_{\mathrm{em}} 540 \mathrm{~nm}\right)$ & & \\
\hline & & & & $377 \mu \mathrm{s}\left(\lambda_{\mathrm{em}} 655 \mathrm{~nm}\right)$ & & \\
\hline
\end{tabular}




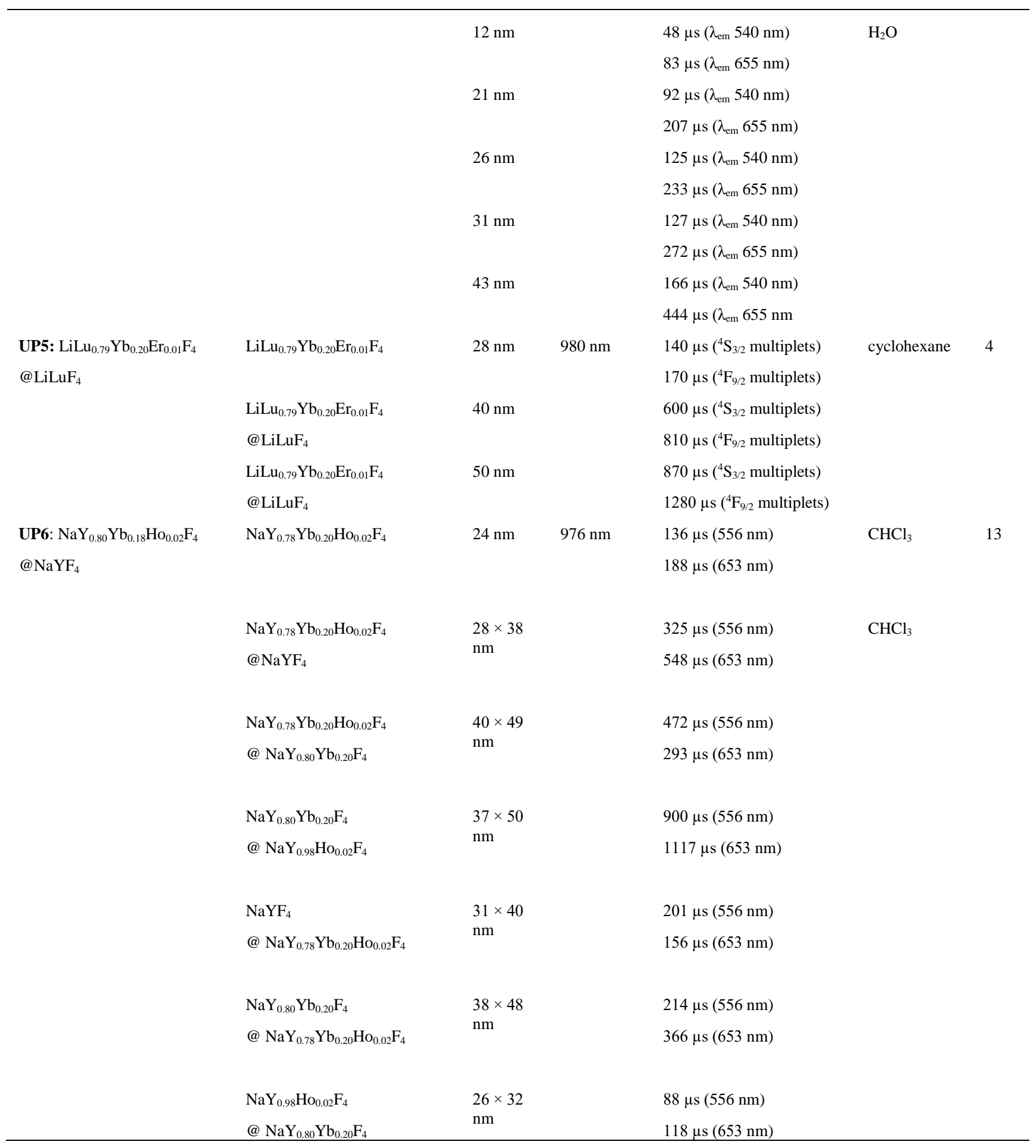




\subsection{Nanoparticle coating with a carboxylated silica shell}

UPs were coated with a carboxylated silica shell using a microemulsion technique. ${ }^{[1,18]}$ The protocol was adjusted to account for different sizes of UPs, as shown in Table S1. UPs were diluted in cyclohexane with Igepal CO-520 and tetraethyl orthosilicate and stirred with high intensity for $10 \mathrm{~min}$. The microemulsion was created after adding an aqueous ammonium hydroxide $12 \%(\mathrm{w} / \mathrm{v})$. The resulting mixture was slowly stirred for 18 hours. Another volume of tetraethyl orthosilicate was added, and the microemulsion was slowly stirred for 4 hours. Carboxyethylsilanetriol sodium salt ( $25 \% \mathrm{w} / \mathrm{v}$ in water) was added, and the cloudy emulsion was sonicated for 15 min and further stirred for $60 \mathrm{~min}$. Carboxylated UPs were extracted by adding dimethylformamide and washed five times with acetone and three times with water. Carboxylated UPs were stored at laboratory temperature as aqueous dispersions.

\subsection{Estimation of UP mass concentration}

For estimating UP mass concentrations, the volume of $200 \mu \mathrm{L}$ of nanoparticle dispersion in water or cyclohexane was dispensed into glass vials. The vials were placed first on a heater to evaporate dispersant and then for 3 hours in an oven $\left(450^{\circ} \mathrm{C}\right)$. Estimated UP masses were used for estimating mass concentrations.

Table S3. Silica coating of photon-upconversion nanoparticles.

\begin{tabular}{|c|c|c|c|c|c|c|}
\hline & UP1 & UP2 & UP3 & UP4 & UP5 & UP6 \\
\hline UPs & $10 \mathrm{mg}$ & $10 \mathrm{mg}$ & $10 \mathrm{mg}$ & $10 \mathrm{mg}$ & $10 \mathrm{mg}$ & $10 \mathrm{mg}$ \\
\hline Igepal CO-520 & $359 \mathrm{mg}$ & $414 \mathrm{mg}$ & $637 \mathrm{mg}$ & $412 \mathrm{mg}$ & $325 \mathrm{mg}$ & $241 \mathrm{mg}$ \\
\hline $\begin{array}{l}\text { Cyclohexane (including UP } \\
\text { dispersion volume) }\end{array}$ & $4.55 \mathrm{~mL}$ & $5.25 \mathrm{~mL}$ & $8.0 \mathrm{~mL}$ & $5.23 \mathrm{~mL}$ & $4.13 \mathrm{~mL}$ & $3.06 \mathrm{~mL}$ \\
\hline $\begin{array}{l}\text { Tetraethyl orthosilicate (the first } \\
\text { addition) }\end{array}$ & $20 \mu \mathrm{L}$ & $23.1 \mu \mathrm{L}$ & $35.5 \mu \mathrm{L}$ & $23.0 \mu \mathrm{L}$ & $18.1 \mu \mathrm{L}$ & $13.4 \mu \mathrm{L}$ \\
\hline $\mathrm{NH}_{4} \mathrm{OH} 12 \%(\mathrm{w} / \mathrm{v})$ & $22 \mu \mathrm{L}$ & $25.4 \mu \mathrm{L}$ & $39.0 \mu \mathrm{L}$ & $25.3 \mu \mathrm{L}$ & $19.9 \mu \mathrm{L}$ & $14.8 \mu \mathrm{L}$ \\
\hline $\begin{array}{l}\text { Tetraethyl orthosilicate (the second } \\
\text { addition) }\end{array}$ & $5 \mu \mathrm{L}$ & $5.8 \mu \mathrm{L}$ & $8.9 \mu \mathrm{L}$ & $5.8 \mu \mathrm{L}$ & $4.6 \mu \mathrm{L}$ & $3.4 \mu \mathrm{L}$ \\
\hline $\begin{array}{l}\text { Carboxyethylsilanetriol, sodium } \\
\text { salt; } 25 \%(\mathrm{w} / \mathrm{v}) \text { in water }\end{array}$ & $10 \mu \mathrm{L}$ & $11.6 \mu \mathrm{L}$ & $17.9 \mu \mathrm{L}$ & $11.6 \mu \mathrm{L}$ & $9.1 \mu \mathrm{L}$ & $6.8 \mu \mathrm{L}$ \\
\hline
\end{tabular}

Table S4. Hydrodynamic diameters estimated by dynamic light scattering.

\begin{tabular}{lllll}
\hline & \multicolumn{2}{l}{ Oleic acid coated in cyclohexane } & \multicolumn{2}{l}{ Carboxylated silica coated in water } \\
\hline & $\begin{array}{l}\text { Hydrodynamic } \\
\text { diameter }(\mathrm{nm})\end{array}$ & Polydispersity index & $\begin{array}{l}\text { Hydrodynamic } \\
\text { diameter }(\mathrm{nm})\end{array}$ & Polydispersity index \\
\cline { 2 - 5 } UP1 & 28.4 & 0.151 & 39.4 & 0.146 \\
UP2 & 24.6 & 0.208 & 34.1 & 0.120 \\
UP3 & 15.4 & 0.243 & 28.5 & 0.262 \\
UP4 & 24.7 & 0.058 & 34.3 & 0.046 \\
UP5 & 31.3 & 0.182 & 39.0 & 0.183 \\
UP6 & 42.2 & 0.332 & 56.5 & 0.128 \\
\hline
\end{tabular}

Table S5. Emission maxima of photon-upconversion nanoparticles.

\begin{tabular}{llll}
\hline & Activator & Composition & Emission maxima $(\mathrm{nm})^{\mathrm{a})}$ \\
\hline $\mathrm{UP1}$ & $\mathrm{Tm}^{3+}$ & $\mathrm{NaY}_{0.80} \mathrm{Yb}_{0.18} \mathrm{Tm}_{0.02} \mathrm{~F}_{4}$ & $450,474,802$ \\
$\mathrm{UP2}$ & $\mathrm{Tm}^{3+}$ & $\mathrm{NaY}_{0.80} \mathrm{Yb}_{0.198} \mathrm{Tm}_{0.002} \mathrm{~F}_{4}$ & $449,474,645,742,778,801$ \\
$\mathrm{UP3}$ & $\mathrm{Tm}^{3+}$ & $\mathrm{NaYb}_{0.998} \mathrm{Tm}_{0.002} \mathrm{~F}_{4} @ \mathrm{CaF}_{2}$ & $479,649,769,788$ \\
$\mathrm{UP} 4$ & $\mathrm{Er}^{3+}$ & $\mathrm{NaY}_{0.80} \mathrm{Yb}_{0.18} \mathrm{Er}_{0.02} \mathrm{~F}_{4}$ & $520,528,540,550,654,660,698,842$ \\
$\mathrm{UP5}$ & $\mathrm{Er}^{3+}$ & $\mathrm{LiLu}_{0.79} \mathrm{Yb}_{0.20} \mathrm{Er}_{0.01} \mathrm{~F}_{4} @ \mathrm{LiLuF}_{4}$ & $521,529,541,550,652,668,699,839,852$ \\
$\mathrm{UP6}$ & $\mathrm{Ho}^{3+}$ & $\mathrm{NaY}_{0.80} \mathrm{Yb}_{0.18} \mathrm{Ho}_{0.02} \mathrm{~F}_{4} @ \mathrm{NaYF}_{4}$ & $485,538,578,644,749$ \\
\hline
\end{tabular}

a)Maxima for nanoparticles coated by carboxylated silica shell in water 


\section{Microfluidic chip fabrication}

\subsection{Chip design}

Microchannel architecture with five water phase inputs, one oil phase input, a cross-junction (droplet formation), and a passive mixer was designed in AutoCAD ${ }^{\circledR}$ software (Autodesk 2015, Figure S1). ${ }^{[19]}$ The detection was carried out from a part of the channel, which was approximately 2-3 $\mathrm{mm}$ out from the mixer part. The depth of $100 \mu \mathrm{m}$ was constant for all channels. The width of channels varied from $20 \mu \mathrm{m}$ in the water phase confluence to $125 \mu \mathrm{m}$ in the mixing and detection part of the chip (Figure S2). Chip design was photolithographically transferred onto Photomask Blank Plates (Nanofilm, USA) using a high-resolution laser printer (Heidelberg $\mu$ PG 101 Laser Writer, Heidelberg Instruments Mikrotechnik GmbH, Germany).

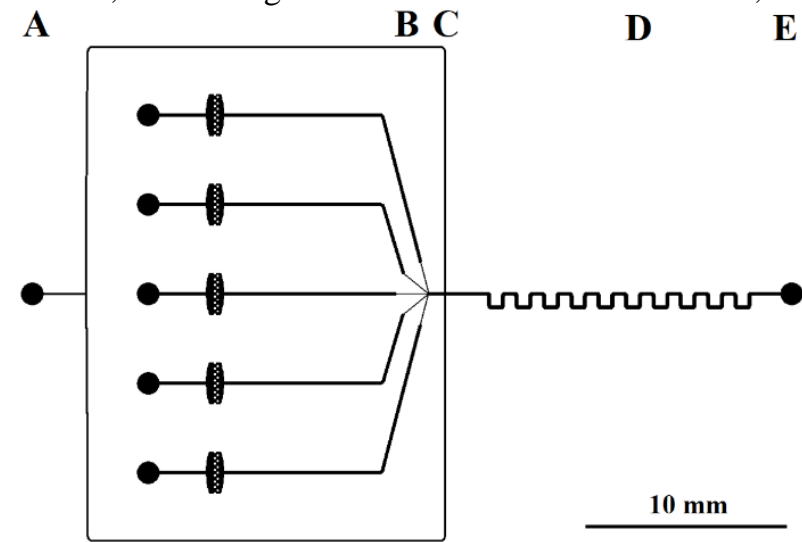

Figure S1. Design of the microfluidic chip: A) oil inlet; B) inlets for water dispersions with confluence; C) crossjunction; D) passive mixer; E) Output.

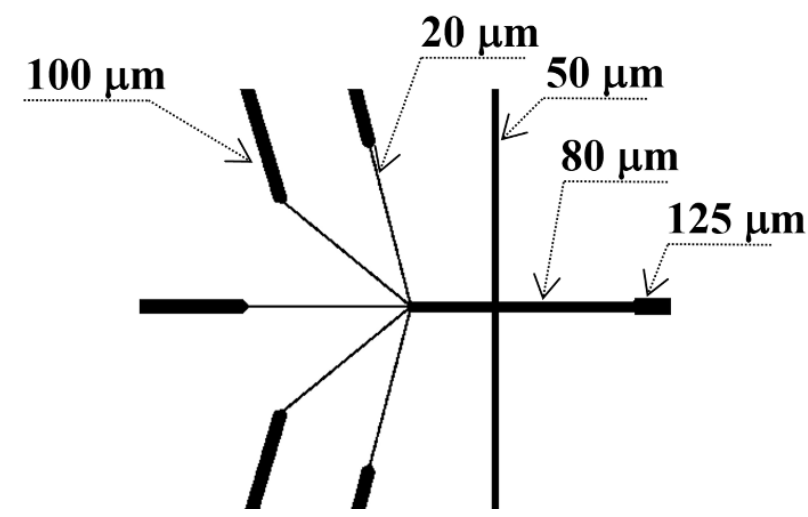

Figure S2. Detail of the chip confluence and cross-junction, the labels mark the widths of channels.

\section{$3.2 \mathrm{SU}-8$ mold development}

The negative photoresist SU-8 3050 (MicroChem Corp., USA) was coated on a glass substrate (Boro Glass Slides, $4 \times 4 \times 0.06$ "; MB Whitaker \& Associates, Germany), which was cleaned with piranha solution $\left(\mathrm{H}_{2} \mathrm{SO}_{4}: \mathrm{H}_{2} \mathrm{O}_{2} 3\right.$ : $1(\mathrm{v} / \mathrm{v}))$. The photoresist was spin-coated by ramping from speed $500 \mathrm{rpm}$ to the final speed of $3000 \mathrm{rpm}$ within $10 \mathrm{~s}$ and then holding at this speed for $30 \mathrm{sec}$. The substrate bearing the layer of photoresist was baked at $65^{\circ} \mathrm{C}$ for $10 \mathrm{~min}$, at $95{ }^{\circ} \mathrm{C}$ for $30 \mathrm{~min}$ and lastly at $65^{\circ} \mathrm{C}$ for $5 \mathrm{~min}$. After cooling, photomask was placed on the SU-8 coated substrate and exposed to the UV light with an exposure energy of $250 \mathrm{~mJ} \mathrm{~cm}^{-2}$. After exposure, the substrate was baked for $1 \mathrm{~min}$ at $65^{\circ} \mathrm{C}$ and for $10 \mathrm{~min}$ at $95^{\circ} \mathrm{C}$. Finally, the mold was developed by ma-600 SU-8 developer (MicroChem Corp.) and washed with isopropyl alcohol.

\subsection{PDMS chip fabrication}

SYLGARD 184 kit (Dow Corning, Midland, MI, USA) was used for polydimethylsiloxane (PDMS) chip fabrication with $1 / 10(\mathrm{w} / \mathrm{w})$ ratio of curing agent. PDMS mixture was poured over the SU-8 master mold and cured for 2 hours at $70^{\circ} \mathrm{C}$. After cooling, holes for channels inlets were punched by biopsy punch (Miltex, $1.5 \mathrm{~mm}$ diameter) and PDMS chip was attached on a microscope slide $(76 \times 26 \mathrm{~mm}$, Corning Glass $)$ by plasma bonding. Immediately, the chip was manually flushed with a mixture of a fluorinated oil FC-40 (3M FluorinertTM FC-40, Sigma Aldrich) supplemented with 2\% 1H,1H,2H,2H-perfluorodecyltrichlorosilane (Sigma Aldrich) for 5 minutes followed by 1 hour of washing $\left(250 \mu \mathrm{L} \mathrm{h}^{-1}\right)$ with the pure fluorinated oil FC-40. Prepared chip was cured at $65^{\circ} \mathrm{C}$ for 1 hour. 


\subsection{Device integration}

The set of silica capillaries with a length of $50 \mathrm{~cm}$ and $25 \mu \mathrm{m}$ inner diameters (Molex) were used for connecting water phases. For connecting the oil phase, a capillary with a length of $50 \mathrm{~cm}$ and $100 \mu \mathrm{m}$ inner diameter was used. The ends of capillaries ( $2 \mathrm{~cm}$ length) were tightly fitted with polytetrafluoroethylene tubes, which served as robust connectors for PDMS chip (1/16" outer diameter and 0.01 inner diameter; Alltech). The flow rates were precisely controlled by laboratory made pressure controller. ${ }^{[20]}$

\subsection{Monte Carlo simulation}

It was of our great interest to inspect the precision and accuracy of relative UP concentrations $\left(c_{U P x}\right)$ estimates based solely on spectra - it means without imprecision of calibration, reflections on surfaces, laser intensity fluctuations, etc. Therefore, we made a Monte Carlo simulation. Similar to microtiter plate experiment (described in the main text), we simulated emission spectra of UP mixtures containing high concentrations of all UPs (relative concentration 1.0) but one UP type, which was variable (relative concentration 0.0-1.0). Such virtual spectra were created as a linear combination of spectra recorded from droplets containing the pure dispersion of UP1-6. We eventually added noise to these spectra, which resembled a typical microfluidic measurement: With integration time $20 \mathrm{~ms}$, we found a dependence between intensity and measurement noise as it is shown in Figure S3. Those simulated spectra - spectra from "unknown" samples - were analyzed by non-negative least square algorithm resulting in the estimate of UP concentrations in simulated "unknown" sample. The precision of estimates was evaluated from ten thousands of Monte Carlo trials for each simulated UP mixture. We found that the standard deviation of estimated relative concentrations depends on the similarity of UP emission spectra (Figure S4). The most precise estimates of relative concentrations were for UP1, UP4, UP5, and UP6 (maximal standard deviation of estimated relative concentrations were $0.0020,0.0025,0.0025$, and 0.0019 , respectively). The least precision still very good - was found for relative concentrations of UP2 and UP3, which emits the most similar spectra (maximal standard deviation of estimated relative concentrations were 0.0054 and 0.0048 , respectively).

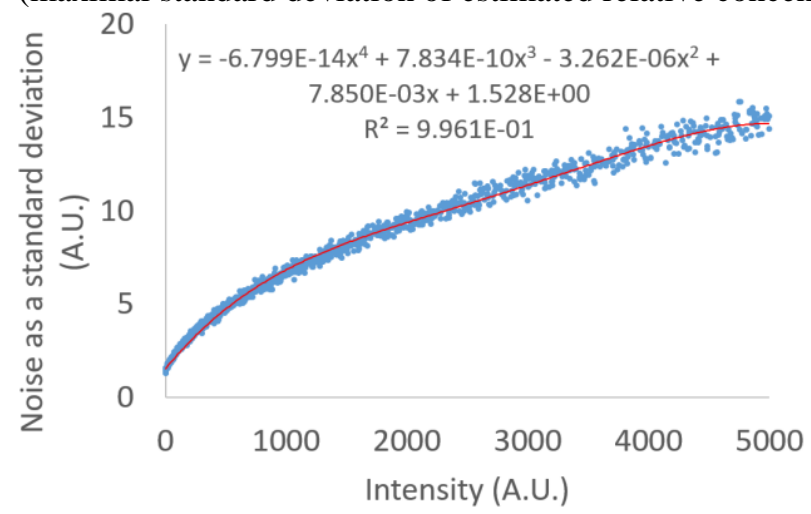

Figure S3. Dependence of measurement noise on measured intensity for wavelengths from 430 to $875 \mathrm{~nm}$. The dependence of noise on measured intensity with integration time $20 \mathrm{~ms}$ was plotted for CCD array spectroscope QE65000 (Ocean Optics) and fitted with a polynomial model.

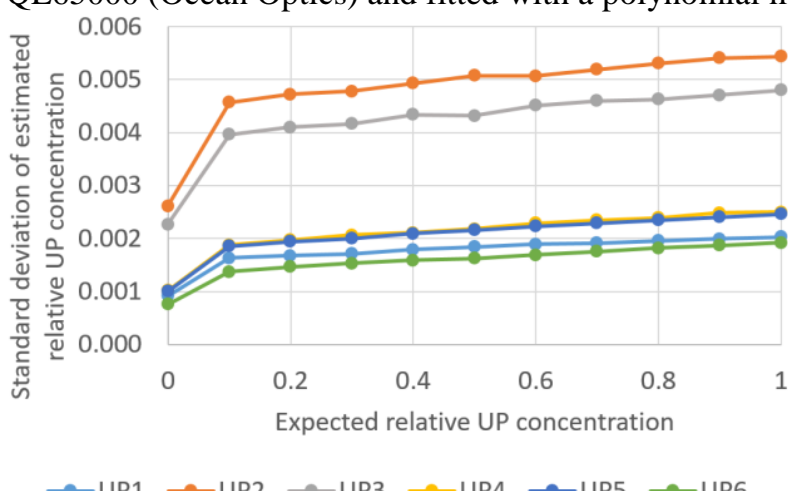

Figure S4. Monte Carlo simulation of the precision of estimates of relative UP concentrations. We found that the most precise estimates of relative concentrations were for UP1, UP4, UP5, and UP6 (maximal standard deviation of estimated relative concentrations were $0.0020,0.0025,0.0025$, and 0.0019 , respectively). The least precision still very good - was found for relative concentrations of UP2 and UP3, which emit the most similar spectra (maximal standard deviation of estimated relative concentrations were 0.0054 and 0.0048 , respectively). 


\section{References}

1) Hlaváček, A., Farka, Z., Hübner, M., Horňáková, V., Němeček, D., Niessner, R., Skládal, P., Knopp, D., Gorris, H.H. Competitive Upconversion-Linked Immunosorbent Assay for the Sensitive Detection of Diclofenac (2016) Analytical Chemistry, 88 (11), pp. 6011-6017. DOI: 10.1021/acs.analchem.6b01083.

2) Wang, F., Han, Y., Lim, C.S., Lu, Y., Wang, J., Xu, J., Chen, H., Zhang, C., Hong, M., Liu, X. Simultaneous phase and size control of upconversion nanocrystals through lanthanide doping (2010) Nature, 463 (7284), pp. 1061-1065. DOI: 10.1038/nature08777.

3) Chen, G., Shen, J., Ohulchanskyy, T.Y., Patel, N.J., Kutikov, A., Li, Z., Song, J., Pandey, R.K., Agren, H., Prasad, P.N., Han, G. $\left(\alpha-\mathrm{NaYbF}_{4}: \mathrm{Tm}^{3+}\right) / \mathrm{CaF}_{2}$ core/shell nanoparticles with efficient near-infrared to near-infrared upconversion for highcontrast deep tissue bioimaging (2012) ACS Nano, 6 (9), pp. 8280-8287. DOI: 10.1021/nn302972r.

4) Huang, P., Zheng, W., Zhou, S., Tu, D., Chen, Z., Zhu, H., Li, R., Ma, E., Huang, M., Chen, X. Lanthanide-doped LiLuF4 Upconversion nanoprobes for the detection of disease biomarkers (2014) Angewandte Chemie - International Edition, 53 (5), pp. 1252-1257. DOI: 10.1002/anie.201309503.

5) Xu, C.T., Svenmarker, P., Liu, H., Wu, X., Messing, M.E., Wallenberg, L.R., Andersson-Engels, S. High-resolution fluorescence diffuse optical tomography developed with nonlinear upconverting nanoparticles (2012) ACS Nano, 6 (6), pp. 4788-4795. DOI: $10.1021 / \mathrm{nn} 3015807$.

6) Liu, H., Xu, C.T., Lindgren, D., Xie, H., Thomas, D., Gundlach, C., Andersson-Engels, S. Balancing power density based quantum yield characterization of upconverting nanoparticles for arbitrary excitation intensities (2013) Nanoscale, 5 (11), pp. 4770-4775. DOI: 10.1039/c3nr00469d.

7) Mousavi, M., Thomasson, B., Li, M., Kraft, M., Würth, C., Resch-Genger, U., Andersson-Engels, S. Beam-profilecompensated quantum yield measurements of upconverting nanoparticles (2017) Physical Chemistry Chemical Physics, 19 (33), pp. 22016-22022. DOI: 10.1039/c7cp03785f.

8) Meijer, M.S., Rojas-Gutierrez, P.A., Busko, D., Howard, I.A., Frenzel, F., Würth, C., Resch-Genger, U., Richards, B.S., Turshatov, A., Capobianco, J.A., Bonnet, S. Absolute upconversion quantum yields of blue-emitting $\mathrm{LiYF}_{4}: \mathrm{Yb}^{3+}, \mathrm{Tm}^{3+}$ upconverting nanoparticles (2018) Physical Chemistry Chemical Physics, 20 (35), pp. 22556-22562. DOI: 10.1039/c8cp03935f.

9) Kaiser, M., Würth, C., Kraft, M., Hyppänen, I., Soukka, T., Resch-Genger, U. Power-dependent upconversion quantum yield of $\mathrm{NaYF}_{4}: \mathrm{Yb}^{3+}, \mathrm{Er}^{3+}$ nano- and micrometer-sized particles-measurements and simulations (2017) Nanoscale, 9 (28), pp. 10051-10058. DOI: 10.1039/c7nr02449e.

10) Boyer, J.-C., Van Veggel, F.C.J.M. Absolute quantum yield measurements of colloidal $\mathrm{NaYF}_{4}: \mathrm{Er}^{3+}, \mathrm{Yb}^{3+}$ upconverting nanoparticles (2010) Nanoscale, 2 (8), pp. 1417-1419. DOI: 10.1039/c0nr00253d.

11) Würth, C., Kaiser, M., Wilhelm, S., Grauel, B., Hirsch, T., Resch-Genger, U. Excitation power dependent population pathways and absolute quantum yields of upconversion nanoparticles in different solvents (2017) Nanoscale, 9 (12), pp. 4283-4294. DOI: 10.1039/c7nr00092h.

12) Kaiser, M., Würth, C., Kraft, M., Soukka, T., Resch-Genger, U. Explaining the influence of dopant concentration and excitation power density on the luminescence and brightness of $\beta-\mathrm{NaYF}_{4}: \mathrm{Yb}^{3+}, \mathrm{Er}^{3+}$ nanoparticles: Measurements and simulations (2019) Nano Research, 12 (8), pp. 1871-1879. 10.1007/s12274-019-2450-4.

13) Pilch, A., Würth, C., Kaiser, M., Wawrzyńczyk, D., Kurnatowska, M., Arabasz, S., Prorok, K., Samoć, M., Strek, W., Resch-Genger, U., Bednarkiewicz, A. Shaping Luminescent Properties of $\mathrm{Yb}^{3+}$ and $\mathrm{Ho}^{3+} \mathrm{Co}-$ Doped Upconverting CoreShell $\beta-\mathrm{NaYF}_{4}$ Nanoparticles by Dopant Distribution and Spacing (2017) Small, 13 (47), art. no. 1701635, . DOI: $10.1002 / \mathrm{smll} .201701635$

14) Arppe, R., Hyppänen, I., Perälä, N., Peltomaa, R., Kaiser, M., Würth, C., Christ, S., Resch-Genger, U., Schäferling, M., Soukka, T. Quenching of the upconversion luminescence of $\mathrm{NaYF}_{4}: \mathrm{Yb}^{3+}, \mathrm{Er}^{3+}$ and $\mathrm{NaYF}_{4}: \mathrm{Yb}^{3+}, \mathrm{Tm}^{3+}$ nanophosphors by water: The role of the sensitizer $\mathrm{Yb}^{3+}$ in non-radiative relaxation (2015) Nanoscale, 7 (27), pp. 11746-11757. DOI: $10.1039 / \mathrm{c} 5 \mathrm{nr} 02100 \mathrm{f}$.

15) Lu, Y., Zhao, J., Zhang, R., Liu, Y., Liu, D., Goldys, E.M., Yang, X., Xi, P., Sunna, A., Lu, J., Shi, Y., Leif, R.C., Huo, Y., Shen, J., Piper, J.A., Robinson, J.P., Jin, D. Tunable lifetime multiplexing using luminescent nanocrystals (2014) Nature Photonics, 8 (1), pp. 32-36. DOI: 10.1038/nphoton.2013.322.

16) Gargas, D.J., Chan, E.M., Ostrowski, A.D., Aloni, S., Altoe, M.V.P., Barnard, E.S., Sanii, B., Urban, J.J., Milliron, D.J., Cohen, B.E., Schuck, P.J. Engineering bright sub-10-nm upconverting nanocrystals for single-molecule imaging (2014) Nature Nanotechnology, 9 (4), pp. 300-305. DOI: 10.1038/nnano.2014.29.

17) Kraft, M., Würth, C., Muhr, V., Hirsch, T., Resch-Genger, U. Particle-size-dependent upconversion luminescence of $\mathrm{NaYF}_{4}$ : Yb, Er nanoparticles in organic solvents and water at different excitation power densities (2018) Nano Research, 11 (12), pp. 6360-6374. DOI: 10.1007/s12274-018-2159-9.

18) Hlaváček, A., Sedlmeier, A., Skládal, P., Gorris, H.H. Electrophoretic characterization and purification of silica-coated photon-upconverting nanoparticles and their bioconjugates (2014) ACS Applied Materials and Interfaces, 6 (9), pp. 69306935. DOI: 10.1021/am500732y.

19) Křivánková, J., Přikryl, J. Hlaváček, A. Droplet-based microfluidic chip with passive mixer for analysis with photonupconversion nanoparticles. CECE 2018. 15th International Interdisciplinary Meeting on Bioanalysis. p. 202-205. ISBN 97880-904959-5-1.

20) Přikryl, J., Křivánková, J., Hlaváček, A. Arduino-based pressure-driven flow controller for droplet microfluidics. CECE 2018. 15th International Interdisciplinary Meeting on Bioanalysis. p. 249-251. ISBN 978-80-904959-5-1. 